\title{
Acoustic signals in the sand fly Lutzomyia (Nyssomyia) intermedia (Diptera: Psychodidae)
}

Felipe M Vigoder ${ }^{1 *}$, Nataly A Souza ${ }^{2}$ and Alexandre A Peixoto ${ }^{1,3}$

\begin{abstract}
Background: Acoustic signals are part of the courtship of many insects and they often act as species-specific signals that are important in the reproductive isolation of closely related species. Here we report the courtship songs of the sand fly Lutzomyia (Nyssomyia) intermedia, one of the main vectors of cutaneous leishmaniasis in Brazil.

Findings: Recordings were performed using insects from three localities from Eastern Brazil: Posse and Jacarepaguá in Rio de Janeiro State and Corte de Pedra in Bahia State. The three areas have remnants of the Brazilian Atlantic forest, they are endemic for cutaneous leishmaniasis and L. intermedia is the predominant sand fly species. We observed that during courtship L. intermedia males from all populations produced pulse songs consisting of short trains. No significant differences in song parameters were observed between the males of the three localities.

Conclusions: L. intermedia males produce acoustic signals as reported for some other sand flies such as the sibling species of the Lutzomyia longipalpis complex. The lack of differences between the males from the three localities is consistent with previous molecular studies of the period gene carried out in the same populations, reinforcing the idea that L. intermedia is not a species complex in the studied areas and that the three populations are likely to have similar vectorial capacities.
\end{abstract}

\section{Findings}

Understanding sexual behavior of insect vectors is important as it can be a possible target for disease control $[1,2]$. Acoustic signals in intraspecific communication of insects is frequently associated with mating [3,4] and they often act as species-specific signals either for long range attraction, e.g. crickets [5], or in close range recognition and stimulation, e.g. fruit flies [6].

Many vector species also produce songs as part of their mating behavior [7-9]. In the sand fly Lutzomyia longipalpis s.l., main vector of American visceral leishmaniasis, the male lovesong has proven to be a good marker to distinguish the Brazilian cryptic species of this complex [10-12]. Songs have also been reported from two other Neotropical sand fly species: Lutzomyia cruzi and Lutzomyia migonei $[13,14]$.

\footnotetext{
* Correspondence: fvigoder@gmail.com

'Laboratório de Biologia Molecular de Insetos, Instituto Oswaldo Cruz, FIOCRUZ, Av. Brasil 4365, Manguinhos, CEP 21040-360, Rio de Janeiro, RJ, Brazil

Full list of author information is available at the end of the article
}

Lutzomyia (Nyssomyia) intermedia, or Nyssomyia intermedia [15], is one of the main vectors of cutaneous leishmaniasis in Brazil [16]. Two other species very closely related to $L$. intermedia are also important vectors of cutaneous leishmaniasis, Lutzomyia neivai and Lutzomyia whitmani [16-18]. The first one has a more limited distribution being found in more southern regions of Brazil and northern Argentina, while the second one has a larger distribution and is found in sympatry with $L$. intermedia and L. neivai in many regions [17].

Despite its epidemiological importance very little is known about the sexual behavior of $L$. intermedia. Here we report the songs produced by males of $L$. intermedia from three different populations from Eastern Brazil.

Insects used in the present study were collected in the localities of Posse (Petrópolis, Rio de Janeiro State), Jacarepaguá (Rio de Janeiro, Rio de Janeiro State) and Corte de Pedra (Presidente Tancredo Neves, Bahia State). The three areas have remnants of the Brazilian Atlantic forest, they are endemic for cutaneous
C Biomed Central

C 2011 Vigoder et al; licensee BioMed Central Ltd. This is an Open Access article distributed under the terms of the Creative Commons Attribution License (http://creativecommons.org/licenses/by/2.0), which permits unrestricted use, distribution, and reproduction in any medium, provided the original work is properly cited. 
leishmaniasis and L. intermedia is the predominant sand fly species.

The sand flies were identified according to Young \& Duncan [19] and Marcondes [17] and the F1 of wildcaught females were used in the experiments. Sand flies were raise in constant temperature $\left(25^{\circ} \mathrm{C} \pm 1^{\circ} \mathrm{C}\right)$ with humidity close to saturation using the same protocol used for L. longipalpis [20].

The recordings of the acoustic signals were also carried out at $25^{\circ} \mathrm{C} \pm 1^{\circ} \mathrm{C}$ using an INSECTAVOX microphone [21], a Sony Hi8CCD-TRV65 video camera and Sony SLV-77HFBR VCR with a virgin couple of the same population in each trial as described in Souza et al. [11]. Each recording lasted about 5 minutes and male wing vibration towards the female was observed in about $20 \%$ of the trials. Although no copulation was observed in any of the trials, this song appears to be part of the courtship as the males start to sing when they are facing the female's side moving simultaneously towards her back. The recorded songs were digitalized using a CED1401 A/D converter and the analysis was performed using the Spike2 software (version 4.08), both from Cambridge Electronic Design (UK). Four song parameters were analyzed from each song: inter-pulseinterval (IPI) and train length (TL) measured in milliseconds (ms) and seconds (s), respectively, number of pulses per train (NP) and carrier frequency (FREQ) in Hertz $(\mathrm{Hz})$. The statistics analysis was performed using the software $\mathrm{R}$ [22].

L. intermedia males produce short trains of pulse song (Figure 1$)$. The means $( \pm$ SEM) of the parameters analyzed in the three $L$. intermedia populations are shown in Table 1. Individuals from the population of Posse presented the higher IPI and the shorter trains while

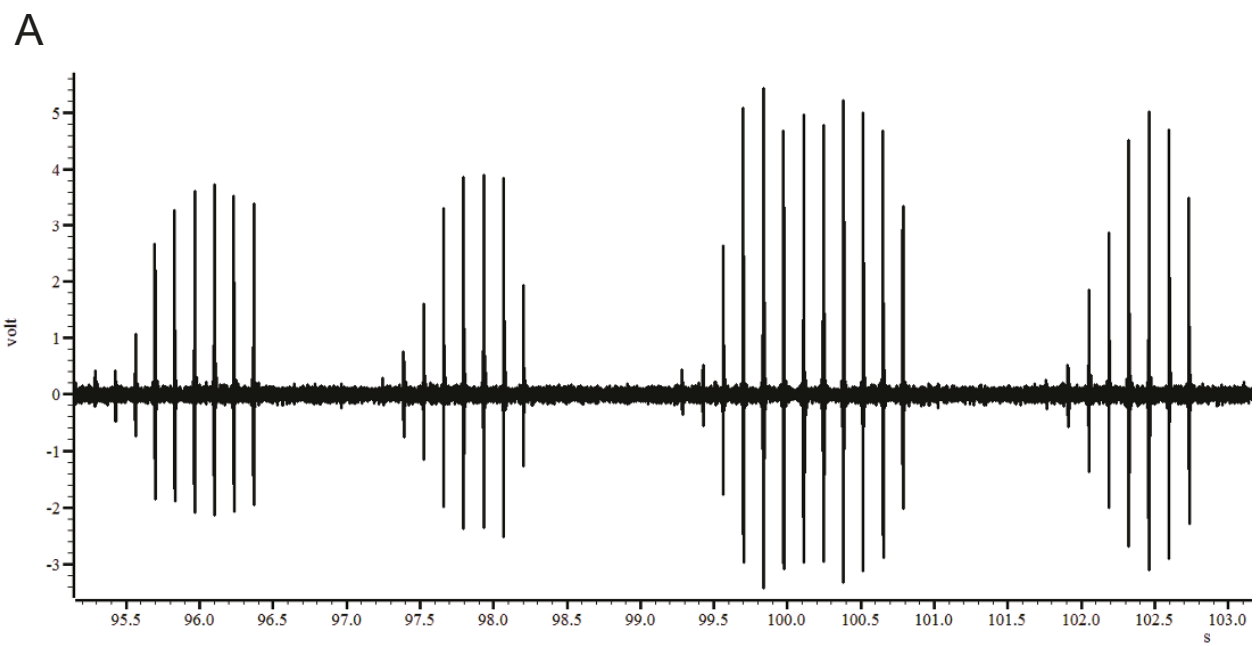

B

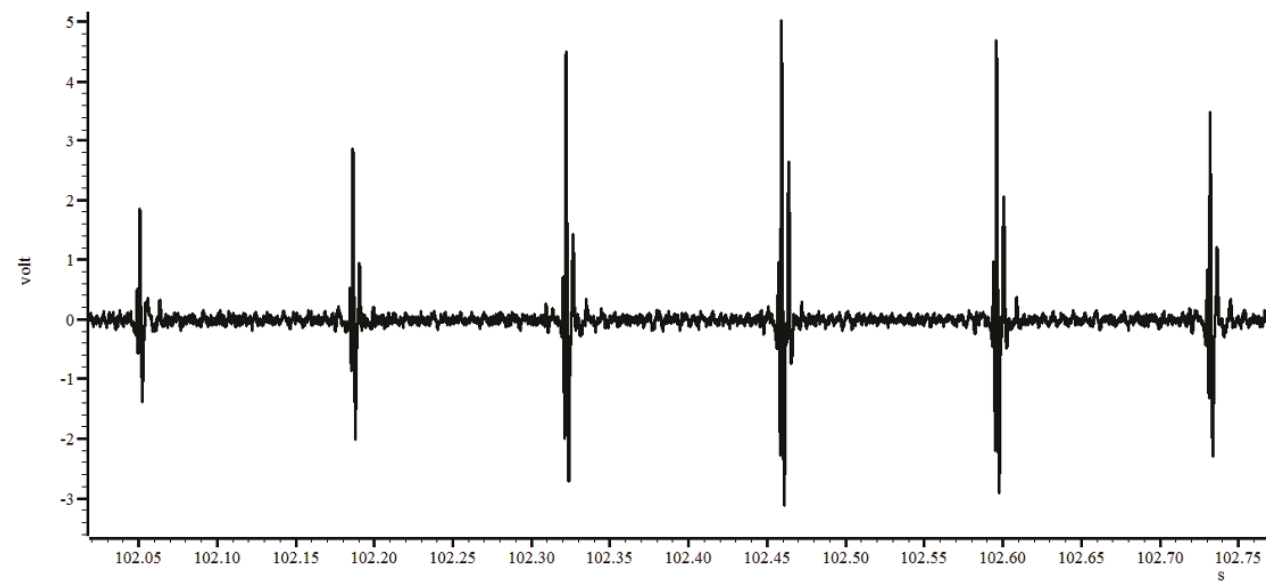

Figure 1 Lutzomyia intermedia male song. Panel (A) shows a segment of 8 seconds of song with 4 trains. Panel (B) shows a single train in more detail. 
Table 1 Mean values ( \pm SEM) for the song parameters from three populations of $L$. intermedia

\begin{tabular}{ccccccc}
\hline & N & IPI $(\mathbf{m s})$ & NP & TL $(\mathbf{s})$ & Freq (Hz) & CPP \\
\hline Jacarepaguá & 3 & $130.12( \pm 3.43)$ & $11.67( \pm 0.33)$ & $1.39( \pm 0.01)$ & $230.04( \pm 4.34)$ & $2.50( \pm 0.16)$ \\
\hline C. de Pedra & 10 & $138.65( \pm 2.21)$ & $10.41( \pm 0.60)$ & $1.30( \pm 0.08)$ & $249.68( \pm 16.48)$ & $2.72( \pm 0.08)$ \\
\hline Posse & 9 & $142.88( \pm 3.16)$ & $8.80( \pm 1.01)$ & $1.11( \pm 0.14)$ & $232.38( \pm 10.97)$ & $2.62( \pm 0.17)$ \\
\hline
\end{tabular}

males from Corte de Pedra showed the higher song frequency. However, ANOVA indicates no significant difference in any of the parameters analyzed (IPI: $\mathrm{F}_{2,21}=$ 2.88, NP: $\mathrm{F}_{2,21}=2.02 ;$ TL: $\mathrm{F}_{2,21}=1.21$; Freq: $\mathrm{F}_{2,21}=$ 0.50 ; CPP: $\mathrm{F}_{2,21}=0.45 ; \mathrm{p}>0.05$ in all cases).

Compared to the songs produced during copulation by L. migonei males [14], the (pre-copulatory) courtship song of L. intermedia has a much larger IPI $(\sim 137 \mathrm{~ms} \times$ $\sim 26 \mathrm{~ms})$, much longer trains $(\sim 1.3 \mathrm{~s} \times \sim 0.15 \mathrm{~s})$ and smaller CPP $(\sim 2.6 \times \sim 3.3)$. The song of L. intermedia males also contrasts with the copulation songs produced by the different L. longipalpis siblings species [10-12], even those producing pulse song which are characterized by shorter IPIs $(<67 \mathrm{~ms})$ and longer trains $(>2.1$ s). Songs produced before and during copulation have probably the same basic function; they are part of the courtship, increasing female's receptivity to insemination and having also a role in reproductive isolation of closely related species.

Since no copulations were observed we cannot be sure the song is really involved in courtship. Another possibility is that it is involved in some form of aggression, such as to protect a territory. However, this behavior is usually a male-male signal [3] and no songs were produced in a couple of trials where two males were used together with a female. Therefore, it seems more likely that songs are part of courtship.

The lack of mating prevented us from verifying whether $L$. intermedia males also produce copulation songs as observed in L. longipalpis s.l., L. cruzi and $L$. migonei [11-14]. In Drosophila, although males of some species sing while in copula [23], in most studied species males only produce courtship songs before attempting copulation [6]. Therefore, although it is possible that $L$. intermedia males also produce copulation songs that is not necessarily the case.

In L. longipalpis s.l. populations the analysis of male lovesongs and the period gene, which is involved in the control of Drosophila courtship song [24], yielded consistent results confirming the existence of a species complex in Brazil [10-12,25,26].

The analysis of the differentiation in the period gene between the L intermedia populations of Posse, Jacarepaguá and Corte de Pedra [18] is also consistent with the song results as the two types of analysis did not indicate significant differentiation, either molecular or behavioral. Therefore, these data together reinforce the idea that, at least for the studied localities, L. intermedia constitutes a single species and that the three populations are likely to have similar vectorial capacities.

\section{Acknowledgements}

This work was supported by grants from the Howard Hughes Medical Institute, CNPq, Faperj, CAPES and FIOCRUZ.

\section{Author details}

${ }^{1}$ Laboratório de Biologia Molecular de Insetos, Instituto Oswaldo Cruz, FIOCRUZ, Av. Brasil 4365, Manguinhos, CEP 21040-360, Rio de Janeiro, RJ, Brazil. 'Laboratório de Transmissores de Leishmanioses, Instituto Oswaldo Cruz, FIOCRUZ, Av. Brasil 4365, Manguinhos, CEP 21040-360, Rio de Janeiro, RJ, Brazil. ${ }^{3}$ Instituto Nacional de Ciência e Tecnologia em Entomologia Molecular, Brazil.

\section{Authors' contributions}

FMV participated in the recordings, performed the song and statistical analysis and drafted the manuscript. NAS collected the insects and participated in the recordings. AAP conceived the study, participated in the recordings and helped to write the manuscript. All authors have read and approved the final manuscript.

\section{Competing interest}

The authors declare that they have no competing interests.

Received: 15 February 2011 Accepted: 13 May 2011

Published: 13 May 2011

\section{References}

1. Pates H, Curtis C: Mosquito behavior and vector control. Annu Rev Entomol 2005, 50:53-70.

2. Ramirez $J L$, Garver LS, Dimopoulos G: Challenges and approaches for mosquito targeted malaria control. Curr Mol Med 2009, 9:116-130.

3. Ewing AW: Arthropod bioacoustics New York: Cornell University Press; 1989.

4. Reinhold K: Variation in acoustic signaling traits exhibits footprints of sexual selection. Evolution 2010.

5. Hedwig B: Pulses, patterns and paths: neurobiology of acoustic behaviour in crickets. J Comp Physiol A Neuroethol Sens Neural Behav Physiol 2006, 192:677-689.

6. Greenspan RJ, Ferveur JF: Courtship in Drosophila. Annu Rev Genet 2000, 34:205-232.

7. Saini RK: Sound production associated with sexual-behavior of the tsetse, Glossina-morsitans-morsitans. Insect Sci Appl 1985, 6:637-644.

8. Clements AN: In The biology of mosquitoes. Volume 2. New York: CABI Publishing; 1999

9. Gibson G, Russell I: Flying in tune: sexual recognition in mosquitoes. Curr Biol 2006, 16:1311-1316.

10. de Souza NA, Ward RD, Hamilton JGC, Kyriacou CP, Peixoto AA: Copulation songs in three siblings of Lutzomyia longipalpis (Diptera: Psychodidae). Trans R Soc Trop Med Hyg 2002, 96:102-103.

11. Souza NA, Vigoder FM, Araki AS, Ward RD, Kyriacou CP, Peixoto AA: Analysis of the copulatory courtship songs of Lutzomyia longipalpis in six populations from Brazil. J Med Entomol 2004, 41:906-913.

12. Araki AS, Vigoder FM, Bauzer LG, Ferreira GE, Souza NA, Araújo IB, Hamilton JG, Brazil RP, Peixoto AA: Molecular and Behavioral Differentiation among Brazilian Populations of Lutzomyia longipalpis (Diptera: Psychodidae: Phlebotominae). PLoS Negl Trop Dis 2009, 3:e365. 
13. Vigoder FM, Araki AS, Bauzer LG, Souza NA, Brazil RP, Peixoto AA: Lovesongs and period gene polymorphisms indicate Lutzomyia cruzi (Mangabeira, 1938) as a sibling species of the Lutzomyia longipalpis (Lutz and Neiva, 1912) complex. Infect Genet Evol 2010, 10:734-739.

14. Vigoder FM, Souza NA, Peixoto AA: Copulatory courtship song in Lutzomyia migonei (Diptera: Psychodidae). Mem Inst Oswaldo Cruz 2010, 105:1065-1067.

15. Galati EAB: Phylogenetic systematics of the Phlebotominae (Diptera, Psychodidae) with emphasis on American groups. Bol Dir Malariol Saneam Amb 1995, 35:133-142.

16. Rangel EF, Lainson R: Proven and putative vectors of American cutaneous leishmaniasis in Brazil: aspects of their biology and vectorial competence. Mem Inst Oswaldo Cruz 2009, 104:937-954.

17. Marcondes CB: A Redescription of Lutzomyia (Nyssomyia) intermedia (Lutz \& Neiva, 1912), and Resurrection of L. neivai (Pinto, 1926) (Diptera, Psychodidae, Phlebotominae). Mem Inst Oswaldo Cruz 1996, 91:457-462.

18. Mazzoni CJ, Souza NA, Andrade-Coelho C, Kyriacou CP, Peixoto AA: Molecular polymorphism, differentiation and introgression in the period gene between Lutzomyia intermedia and Lutzomyia whitmani. BMC Evol Biol 2006, 6:85-96.

19. Young DG, Duncan MA: Guide to the identification and geographic distribution of Lutzomyia sand flies in Mexico, the West Indies, Central and South America (Diptera: Psychodidae). Gainesville: Memories American Entomological Institute No 54 Associated Publishers; 1994

20. Souza NA, Andrade-Coelho CA, Silva VC, Ward RD, Peixoto AA: Life cycle differences among Brazilian sandflies of the Lutzomyia longipalpis sibling species complex. Med Vet Entomol 2009, 23:287-292.

21. Gorczyca M, Hall JC: The INSECTAVOX, an integrated device for recording and amplifying courtship songs of Drosophila. Dros Inf Serv 1987, 66:157-160.

22. R Development Core Team: $R$ : A Language and Environment for Statistical Computing R Foundation for Statistical Computing, Vienna, Austria; 2010 [http://www.R-project.org].

23. Hoikkala A, Crossley S: Copulatory courtship in Drosophila: behavior and songs of Drosophila birchii and Drosophila serrata. J Insect Behav 2000, 13:71-86.

24. Kyriacou CP, Hall JC: Circadian rhythm mutations in Drosophila melanogaster affect short-term fluctuations in the male's courtship song. Proc Natl Acad Sci USA 1980, 77:6729-6733.

25. Bauzer LG, Souza NA, Ward RD, Kyriacou CP, Peixoto AA: The period gene and genetic differentiation between three Brazilian populations of Lutzomyia longipalpis. Insect Mol Biol 2002, 11:315-323.

26. Bauzer LG, Gesto JS, Souza NA, Ward RD, Hamilton JG, Kyriacou CP, Peixoto AA: Molecular divergence in the period gene between two putative sympatric species of the Lutzomyia longipalpis complex. Mol Biol Evol 2002, 19:1624-1627.

doi:10.1186/1756-3305-4-76

Cite this article as: Vigoder et al:: Acoustic signals in the sand fly Lutzomyia (Nyssomyia) intermedia (Diptera: Psychodidae). Parasites \& Vectors 2011 4:76.

\section{Submit your next manuscript to BioMed Central and take full advantage of:}

- Convenient online submission

- Thorough peer review

- No space constraints or color figure charges

- Immediate publication on acceptance

- Inclusion in PubMed, CAS, Scopus and Google Scholar

- Research which is freely available for redistribution

Submit your manuscript at www.biomedcentral.com/submit
Biomed Central 